\title{
Pensando a escrita como uma prática discursiva: implicações para a pesquisa em
} LA

\section{Maria Bernadete Fernandes de Oliveira UFRN}

Considerando que os discursos circulantes na escola são portadores de valor, e pensando a língua escrita como espaço de manifestação de práticas discursivas inter e intra subjetivas, pretendemos, neste trabalho, a partir dos conceitos de linguagem/discurso como uma prática social, trilhar um percurso que apresenta sugestões para a pesquisa desta modalidade de língua, com vistas a contribuir para um ensino/aprendizagem da língua escrita, que permita incluir, através da valorização dos mecanismos enunciativos, atividades argumentativas e dialógicas em sala de aula.

Considering school discourses as signs which carry value, and at the same time, thinking written language as realizations of intra and inter subjective practices, this paper, assuming the conception of language/discourse as a social practice, intends to present suggestions to go beyond on researches about written language, which attempt to contribute, to its teaching and learning process, through the exploration of argumentative and dialogical classroom activities.

\section{Introdução}

Contribuir com um processo de ensino e aprendizagem da produção textual escrita enquanto uma atividade discursiva, portadora de índices de valores sociais e apreciativos, inserindo-se nos marcos de uma pedagogia, na qual, a formação do cidadão crítico, consciente e participante, seja resultante das atividades que se realizam no espaço da própria escola, entendemos ser um dos pilares nos quais deveriam estar assentadas às bases da pesquisa neste campo temático. Neste artigo, o 
que pretendemos expor é nosso pensamento sobre uma das direções que podem ser tomadas pela pesquisa que vise "...sacudir a quietude com que aceitamos o domínio hegemônico da língua como objeto autônomo e do falante como um ente não problemático..." (Faraco, 2001: 6)

Primeiramente faremos uma breve resenha sobre as pesquisas realizadas, nas últimas décadas, em seguida, apresentaremos nossas sugestões para a ampliação desta área de pesquisa, a partir de uma discussão cuja gênese remonta às noções de discurso como prática social e ao dialogismo bakhtiniano, e, por último teceremos algumas considerações sobre as implicações desta tomada de posição face ao ensino da língua escrita.

\section{A pesquisa sobre a produção textual escrita em língua materna}

Uma revisão da literatura sobre as pesquisas realizadas nas últimas décadas sobre o processo ensino e aprendizagem da produção textual escrita em língua materna revela um amplo envolvimento dos pesquisadores com esta temática, ressaltando-se duas vertentes básicas (Oliveira, 1998). De um lado, a evidência do desenvolvimento de pesquisas assentadas em modelos lingüísticos, com vistas a subsidiar outras formas de ser concebido o processo ensino e aprendizagem desta modalidade de língua. Da Lingüística Textual, com ênfase na organização sintático-semântica-pragmática dos textos, focalizando os mecanismos de coesão e coerência (Halliday and Hasan 1976; Beaugrande and Dressler, 1981; van Djik, 1983; Koch e Travaglia, 1989); à influência do dialogismo bakhtiniano (Geraldi, 1991, 1993, 1996); ao olhar "outro" dirigido à problemática do erro, a partir das colocações do paradigma indiciário (Ginzburg, 1980); até as colocações de Vygotsky $(1979,1984)$ e seguidores sobre a escrita em suas faces representacional e comunicacional (Bronckart 1985, 1991; Schneuwly 1985, 1991, Smolka 1988; Góes e Smolka, 1992, 1993 ). De outro, o levantamento aponta para uma forte tendência em investigações do tipo "pesquisa ação" e "pesquisa colaborativa", com a intenção de formular e sugerir procedimentos didáticos, a serem adotados, em sala de aula, a partir de uma concepção de linguagem como uma atividade e realização de um trabalho (Geraldi, 1994), a partir das operações que se realizam sobre, 
com e pela língua, sugerindo, entre outros, a utilização da reescritura e da escrita colaborativa como procedimentos bem sucedidos (Goes, 1993; Cabral 1994; Abaurre e outros, 1997; Silveira, 1998; Garcez, 1998).

Em uma escala menor, surgem ainda, ao final da década passada, pesquisas focalizando os gêneros do discurso ou gêneros textuais, em qualquer de suas formulações, sejam aquelas de gênese bakhtiniana ou não (Brandão,2000).

Nosso passeio revela, portanto, que tem sido e vem sendo exaustivamente investigados os aspectos reproduzíveis da língua, aqueles que remetem para a estruturação e organização sintático-semânticapragmática, evidenciando aquilo que a língua coloca a disposição do usuário para que ele selecione e utilize adequadamente em suas estratégias do dizer.

Em síntese, diríamos que a pesquisa com relação à língua escrita tem avançado no sentido de estudar os "mecanismos de textualização" (Bronckart, 1999), os quais, articulados à progressão do conteúdo temático, organizam os elementos constitutivos do conteúdo, explicitam ou marcam as relações de continuidade, de ruptura ou de contraste, mecanismos estes, que a nosso ver, correspondem, em uma visão bakhtiniana, na explicitação e organização do "querer-dizer" do falante/ escrevente (Oliveira, 1996).

Os resultados destas pesquisas podem ser vislumbrados, de forma mais concreta, nas sugestões constantes do documento elaborado por alguns intelectuais, sob encomenda do Ministério da Educação e Cultura, mais conhecido como "Parâmetros Curriculares para o Ensino Fundamental". Nele, propõe-se que a língua escrita seja estudada e aprendida em seus usos e formas, em seus aspectos discursivos e notacionais, além de ser objeto de análise e reflexão sobre a língua, colocando-se a finalidade da produção de textos como sendo aquela de "...formar escritores competentes, capazes de produzir textos coerentes, coesos e eficazes ...". Define-se competência como a capacidade de selecionar o gênero no qual o discurso se realizará, de planejar o texto em função de seu objetivo e de seu leitor, e de assumir uma atitude metatextual con seu próprio texto, criando-se condições para que a escola realize seu trabalho educativo de formar cidadãos, que tenham condições de assumir a palavra também na sua modalidade escrita.

A nosso ver, contudo, pensar a escola e seu trabalho educativo de formar cidadãos, como tarefa integrante das atividades cotidianas desta 
instituição, e, tendo o processo ensino/aprendizagem da língua escrita como um dos instrumentos para atingir tal objetivo, implica em ir além dos limites da organização sintático-semântica-pragmática do texto. Implica chegar ao discurso, ao que eles revelam, em outras palavras, significa, investigar/ensinar/perceber, a partir das histórias contadas, ouvidas, lidas, escritas, de onde vêm estas histórias, como são parafraseadas, que posições de sujeito estão manifestadas, que valores sociais são atribuídas as vozes nele presentes. Enfim, são estas, algumas das questões que entendemos subjazerem ao conceito de linguagem como uma prática discursiva, conceito aliás presente no documento em questão, mas que, em nosso entendimento carece de pesquisas que possibilitem, em seu conjunto orientar o ensino da produção textual escrita, na direção anunciada.

\section{A escrita como uma prática social}

Ora, quando se pretende adotar uma concepção de escrita como uma prática social, algumas questões devem ser colocadas. Por exemplo, o que se entende por prática social e sua relação com a linguagem? E, ainda mais, como ver as escolas como espaços de produção e legitimação de formas de subjetividade e estilos de vida, como perceber o modo de funcionamento do conhecimento escolar nos processos de construção de identidades, formulações de desejos e necessidades? O que fazer em sala de aula para que o aluno seja sujeito de seu dizer, e para que a escola aceite, como legítimas, as "outras" histórias, aquelas que ela não conhece e que as vezes não estão inscritas nos textos fontes, ou em quaisquer outros que circulam no espaço escolar?

Um primeiro passo, seria pensar a escola como responsável por transmitir uma cultura escolar (Vadermarin, 2000) - valores e normas , através de práticas, concretizadas no cotidiano da sala de aula, que tanto podem assumir o papel de "inculcação" (Bourdieu, 1998), como também podem caminhar, no sentido apontado por Fairclough (1992), qual seja o de contribuir para a mudança social, através de um processo de conscientização crítica da linguagem.

Um outro deslocamento igualmente necessário é o de considerar o discurso como prática social, constituído em processos interacionais, inscrevendo o sujeito do dizer em suas múltiplas posições (Foucault, 
1969). Esta noção de discurso, introduzida nos estudos da linguagem a partir dos textos de Michel Foucault $(1969,1971)$ visa compreender o enunciado em sua singularidade, aquilo que determina sua existência, sua relação com outros enunciados, e, a partir de suas condições de produção, entender porque em determinadas circunstâncias ocorre este enunciado e não qualquer outro, ou seja, reconhecer, o pertencimento ou não do discurso a um campo discursivo. Nesta concepção, as relações discursivas não são internas ou externas ao discurso. Existem nos limites do discurso, são próprias dos discursos, oferecendo a eles seus objetos do dizer, o que possibilita caracterizar o discurso como uma prática, uma vez que estas relações remetem para o dizer, o fazer dizer, relacionando-se a realização de atividades, ações, um modo de comportamento. Inúmeras são as condições para que surja um objeto de discurso, vinculando-se sua existência a um feixe complexo de relações, estabelecidas entre instituições, processos econômicos e técnicos, sistemas de normas, de natureza primária (reais) e secundária (reflexivas), embora as relações que devem ser consideradas como objeto de análise sejam as relações discursivas, aquelas que, explicitam-se a partir das posições de sujeito, múltiplas e dispersas, e que revelam quem fala, por que fala desta forma, com que autoridade, e o lugar de onde se obtém o discurso.

Em Fairclough (1992), encontramos também uma compreensão do discurso como prática social, como um modo de ação no mundo, uma forma de representação, que mantém uma relação dialética com a estrutura social. Desta forma, é que se pode falar do discurso constituir e contribuir para a construção de sujeitos, objetos e conceitos, identidades sociais, relações sociais entre as pessoas e sistemas de conhecimentos e referências. Este conceito de discurso coloca como características da prática social, intervir na vida social em seus vários domínios, econômico, cultural e político, inserindo-se em uma rede de relações juntamente com outras práticas (Chouliaraki e Fairclough ,1999).

O conceito de enunciado e das relações discursivas formulados por Foucault, e aquele do discurso como uma prática social proposto por Fairclough (1992), apresentam suas afinidades com aquele encontrado nos textos de M.Bakhtin ( 1979, 1992). São semelhantes, entre estes autores, às noções de enunciado/discurso como um acontecimento que não se esgota na língua, e que se situa no plano do texto oral/escrito, portanto tratando-se do signo verbal e não de qualquer 
outro, e que apesar de ser único e irreproduzível, é passível de ser copiado ou transformado, remetendo para enunciados anteriores e posteriores (Bakhtin, 1979, 1992), constituindo-se nas práticas sociais.

Se de um lado, Foucault, Fairclough e Bakhtin concordam na conceituação do discurso como prática social, e com o fato de que o discurso constitui e é constituído em processos interacionais, diferenciamse na concepção do sujeito de dizer. A formulação do sujeito do discurso em Foucault remete para a idéia de múltiplas posições de sujeito, em função do lugar de onde este retira seu discurso, dos vários lugares de onde fala, enquanto que para Bakhtin e Fairclough, além destas características, não se pode pensá-lo sem a participação do outro, ainda que este outro seja virtual. A concepção de sujeito vai além de considerálo apenas como posicionado ideologicamente, incorpora o atributo de alguém que seja capaz de agir criativamente, como quer Fairclough (1992:121) "... de realizar suas próprias conexões entre as diversas práticas e ideologias às quais são expostos...", ou no dizer de Bakhtin, de que as palavras do outro introduzem em nossos enunciados "...sua própria expressividade, seu tom valorativo, que assimilamos, reestruturamos, modificamos..." (Bakhtin, 1992 :314).

$\mathrm{O}$ fato portanto, de que a experiência verbal do ser humano toma forma e evolui sob o efeito da interação contínua e permanente com os enunciados individuais do outro, através de um processo de assimilação, mais ou menos criativo, faz Bakhtin (1992) afirmar que, é verdadeiro que nossos enunciados estão repletos de palavras do outros, mas em graus variados, tanto no que concerne à sua assimilação, como ao seu emprego, seja este consciente ou não.

Portanto, de uma velha significação pode surgir uma outra, reestruturando-a, ainda que contraditória. Em síntese, o conceito de enunciado, postulado como um elo na cadeia da comunicação verbal, dirigindo-se para o outro, instaura uma concepção de enunciado que pressupõe enunciadores, parceiros da comunicação verbal, dotados de atitudes compreensiva/produtiva/responsiva ativa, que podem se manifestar de formas diversas, até mesmo através do silêncio.

Uma outra particularidade igualmente importante da linguagem considerada como uma prática discursiva deriva do fato de que ao realizar-se no processo de relação social, todo signo verbal é marcado pelo horizonte social de sua época e de um grupo social determinado, 
emergindo em situações intersubjetivas, e, neste processo, adquirindo e sendo permeado por valores sociais, de tal forma que qualquer conteúdo objetivo expresso compreende sempre uma orientação apreciativa. A este valor do enunciado, faz-se corresponder às necessidades de expressividade do locutor diante do seu objeto temático, contribuindo para suas escolhas lexicais, gramaticais e composicionais, dele tornandose parte constitutiva.. Contudo, a emoção, o juízo de valor, a tomada de posição face são questões alheias ao sistema lingüístico e, apenas podem ser percebidos em uma concepção de linguagem que compreenda o discurso como uma prática social e os enunciados como respostas e antecipações à cadeia infinita dos dizeres, orais e escritos.

\section{Mecanismos para ouvir/ler o que dizem os textos}

Neste segmento, parafraseando Moita Lopes (2001), discutiremos o processo de como passar "do que o texto é para o que o texto diz e significa?" Este o contexto no qual nos apoiaremos para discutir o papel dos mecanismos enunciativos enquanto elementos que possibilitam ao processo ensino e aprendizagem da produção textual escrita superar sua realização apenas como uma atividade repetitiva, tornando-se, de fato, o exercício de uma prática discursiva.

O termo "mecanismos enunciativos", proposto por Bronckart (1999), remete para questões de avaliação, julgamentos, opiniões a respeito da temática tratada, e ao mesmo tempo às próprias fontes dessa avaliação, às instâncias que por elas se responsabilizam, e, às outras vozes. São estes mecanismos, a nosso ver, aqueles que nos permitem reconhecer nos enunciados os valores que permeiam qualquer texto e as relações de poder que nele se refletem. É, portanto, no conceito de vozes e das relações dialógicas formuladas por Bakhtin, que iremos buscar subsídios para este outro momento da pesquisa sobre o ensino da produção textual escrita.

Como nos ensina Bakhtin (1981), é através das vozes, concebidas como manifestações de consciências que dialogam, debatem, confrontamse concordam, silenciam a voz do outro ou a si próprio, que são expressos os valores, plurais ou não, de uma dada época, em uma dada situação, em um dado grupo social. As vozes, personificação de diferentes sujeitos, de diferentes visões de mundo, de opinião, estabelecem entre si um tipo 
de relações, que Bakhtin chama de relações dialógicas, relações extralingüísticas, que, não podem ser separadas do campo do discurso, ou seja, da língua enquanto fenômeno integral concreto, mas que são irredutíveis às relações lógicas ou às concreto-semânticas. São relações possíveis entre enunciados integrais e entre qualquer parte do enunciado, inclusive aquele constituído por uma palavra isolada, desde que nela ouçamos a voz do outro (Bakhtin, 1981).

Em "Estética da Criação Verbal", ele retoma esta idéia ao dizer que... " a relação dialogica entre enunciados, cujo percurso também passa por dentro do enunciado considerado isoladamente, compete à metalingüística...". E, complementa, afirmando que "... as relações de sentido entre enunciados distintos não são de ordem factual-lógica, e sim de ordem dialógica. O sentido se distribui entre as diversas vozes... ... só é possivel entre enunciados proferidos por sujeitos falantes distintos" ( Bakhtin, 1992: 345). Formulando uma compreensão ampla de dialogismo, que vai além da discussão, polêmica, parodia, diz ele,

...o crédito concedido à palavra do outro, a acolhida fervorosa dada à palavra sacra (de autoridade) ... a concordância com suas infinitas gradações... a estratificação de um sentido que se sobrepõe a outro sentido, de uma voz que se sobrepõe a outra voz, ... a compreensão, que ultrapassa os limites da coisa compreendida... estas relaçóes não podem ser resumidas a uma relação puramente lógica, ou a uma relação puramente factual. É aqui que se encontram em toda a sua integridade, posições, pessoas, justamente VOZES (Bakhtin, 1992: 350).

Em cada palavra, ouvem-se/lêem-se vozes anônimas, distantes, as quais mediante sua transformação em uma visão de mundo, um ponto de vista, uma voz social, não se restringem a limites de ordem espacial/ temporal, colocando os enunciados sempre em confrontação de sentidos, de maneira que "... mesmo entre produções verbais profundamente monológicas, observa-se sempre uma relação dialógica.. (Bakhtin,1992: 355).

Portanto, para Bakhtin (1992: 320), as relações dialógicas inter e intra enunciados pressupõem sujeitos, vozes, ainda que como diz ele, 
seja difícil reconhecê-las, face à sua não concretude imediata, por exemplo, em um enunciado do tipo emocional, e, que poderia ser considerado como monológico pela não concretização do interlocutor. O monologismo, no sentido estrito do termo, apenas ocorreria em um contex to fechado, como no caso das relações entre objetos, que deixam de ser consideradas como dialógicas, por não pressupor relações de sentido entre sujeitos, e são estes os casos em que o dialogismo deixa de existir , quando os sujeitos são reficados, ou são coisas, porque, “...o aniquilamento do adversário aniquila também a esfera dialógica que assegura a vida das palavras (Bakhtin, 1992:391).

Bakhtin (1992) faz referência ainda a um grau zero de dialogia, quando as relações dialógicas tornam-se irrealizáveis, face a determinados impedimentos, como por exemplo aquele que acontece em uma conversa entre surdos, na qual não se realiza contacto de sentido entre as réplicas, face à incomunicabilidade provocada pelo impossibilidade de realização da face material do signo, seu significante.

Estas colocações levam-nos a entender que o enunciado pressupõe sempre sujeitos do dizer, cujas vozes expressam valores e estão sempre em algum tipo de relações dialógicas, destacando-se entre elas, aquelas nas quais os sujeitos do dizer dialogam em pé de igualdade, constituindo discursos polifônicos, ou seja, quando existem vozes e consciências plenas, que mantém, com as outras vozes participantes do discurso, uma relação de absoluta igualdade, e cujas personagens principais não são objetos do discurso, não se reificam, pelo contrário, são sujeitos desse discurso.

A linguagem assim pensada apresenta-se para o outro sob a forma de "texto", que nas ciências humanas, não se propõe como um objeto neutro, posto que não é possível nele, eliminar a consciência de seu interlocutor, virtual ou real, nem a presença das vozes alheias. O texto é um "trio", do qual participam o "eu", o "tu" e as "vozes dos outros", pressupõe uma língua, sem a ela restringir-se, podendo sua análise caminhar no sentido dos elementos reproduzíveis, idênticos em todos os textos, como em geral faz a escola, ou, para o "acontecimento", sua face irreproduzível, com sua constituição enquanto enunciado, evento único, elo na cadeia da comunicação verbal, dotado de autoria. Daí, que, a reprodução do texto pelo sujeito é sempre um acontecimento novo, um novo elo na cadeia histórica da comunicação verbal, ou seja, 
o texto em seu funcionamento enquanto enunciado permitirá que o processo ensino/aprendizagem da produção textual escrita se desenvolva na perspectiva de uma atividade discursiva, uma prática social, implicando nos dois momentos da dialogia bakhtiniana (Oliveira, 1996). O primeiro, aquele que instaura o outro no processo discursivo, responsabilizando-se pela explicação de que o ato de escritura é sempre dirigido para um outro, e por todas as operações do "querer-dizer" do locutor, que, como já nos referimos anteriormente, tem sido bastante pesquisado; o segundo, assentado no fato de que qualquer enunciado é permeado por vozes alheias, entre as quais se processam relações dialógicas .

Este segundo momento, aquele que remete para a presença do outro - vozes alheias- nos enunciados, constitui-se, a nosso ver, a instância que vai possibilitar ir além, considerando a produção textual como uma prática discursiva, portadora de valores. Isto porque, são as vozes concebidas como manifestações de consciências que dialogam, debatem, confrontam-se concordam, silenciam a voz do outro ou a si próprio, expressando seus valores, plurais ou não, em uma dada época, em uma dada situação, em um dado grupo social ( Bakhtin, 1981). Se nosso enunciado é permeado pela voz do outro, o que dizem estas vozes, como nos posicionamos face a estas vozes, com as quais nos identificamos e quais assumimos como nossas marcando nossa posições de sujeito? Quais as relações dialógicas que as diferentes vozes travam em nossos enunciados? Como percebermos as vozes nos textos alheios?

Pensamos que uma das possibilidades de encontrar respostas a tais questões seria explorar os mecanismos enunciativos, aqueles que contribuem para o esclarecimento dos posicionamentos enunciativos, das instâncias que assumem o que é enunciado no texto, das vozes que aí se expressam, traduzindo as diversas avaliações, julgamentos, opiniões, sentimentos sobre alguns aspectos do conteúdo temático. São mecanismos configuracionais que funcionam independentemente da progressão do conteúdo temático e de sua organização, ou seja, dos mecanismos de textualização, representados pelas vozes e pelas modalizações (Bronckart, 1999).

Com relação às vozes, Bronckart sugere seu agrupamento em três subconjuntos: a voz do autor empírico; as vozes sociais, vozes de outras pessoas ou de instituições humanas exteriores ao conteúdo temático do 
texto; e, vozes de personagens, isto é das pessoas ou instituições que estão diretamente implicadas no percurso temático. Em seu entendimento, as vozes remetem para a questão da autoria do texto, de quem é seu criador,e, desta forma, para a questão, presente na psicologia sóciointeracionista, relativa ao processo de construção dos conhecimentos humanos e suas representações, suas ações, sempre em interação com as ações e com os discursos dos outros, mesmo que reorganizados, mantendo os traços da alteridade, que lhe é constitutiva. Vozes, são " entidades que assumem a responsabilidade do que é enunciado..." (Bronckart, 1999: 326), podem ser diretas, como nos discursos interativos, reproduzindo turnos de fala, ou podem ser indiretas, presentificando-se em qualquer tipo de discurso, inferíveis ou introduzidos por determinadas expressões da língua.

As modalizações, por sua vez, são as avaliações formuladas sobre aspectos do conteúdo temático, estudadas desde Aristóteles, realizam-se através de vários recursos da língua, como sejam, os tempos do verbo no futuro do pretérito, os auxiliares de modalização (poder, ser preciso, dever); um subconjunto de advérbios, certas frases impessoais e, classicamente apresentam-se agrupadas em quatro subconjuntos:

- as modalizações lógicas, julgamentos sobre o valor de verdade das proposições enunciadas, como certas, prováveis, possíveis;

- as modalizações deônticas, avaliações sobre o que é enunciado à luz dos valores sociais, apresentando os fatos como socialmente proibidos, permitidos, necessários, desejáveis;

- as modalizações apreciativas, julgamento subjetivo, apreciando os fatos como bons, maus, a partir da visão de quem os avalia;

- as modalizações pragmáticas, julgamento sobre uma das facetas das responsabilidades de um personagem em relação ao processo de que é agente, principalmente sobre a capacidade de ação (poder-fazer), intenção (querer-dizer) e as razões (dever-fazer) (Bronckart, 1999).

Esta repartição de vozes, sugeridas por Bronckart, bem como o agrupamento das modalizações de acordo com o padrão clássico, são sugestivas enquanto indicativo de possíveis categorias de análise, contudo a nosso ver, elas devem ser consideradas como complementares, no caso das vozes, ao conceito encontrado em Bakhtin, o qual implica em consciências que dialogam no e através do discurso, estabelecendo relações dialógicas de formas diferenciadas, percorrendo um caminho 
desde as relações do tipo polifônicas, até aquelas que apresentam um grau zero de dialogia (Oliveira, 2001a).

No caso das modalizações, há de se atentar, que, ao se considerar o discurso e suas condições de produção, seja na visão foucaultiana, seja na formulação dialógica de Bakhtin, seja ainda na visão de uma teoria crítica (Fairclough, 1992), estas não podem ser interpretadas como representantes de valores universais, válidas para todos, em todos os momentos, ou mesmo para o mesmo sujeito em todos os seus momentos. Os valores presentes nos textos não devem ser interpretados como "verdades eternas", pelo contrário, ao pensar o enunciado/discurso como acontecimento, que se realiza na interface dos encontros linguagem e realidade, significa também aceitar sua mutabilidade, pluralidade, polissemia, descontinuidade, exatamente pela sua característica de ser forjada na prática social, portanto, constituído a partir de suas condições de produção e de todos os elementos que as envolvem.

\section{Considerações finais}

A afirmação de Geraldi (1991:135), de que "... a produção de textos (orais e escritos) é o ponto de partida e ponto de chegada de todo o processo ensino/aprendizagem da lingua...", funda-se no entendimento de que é no texto que a língua se revela em sua totalidade, quer enquanto conjunto de formas, quer enquanto discurso. É, pois na produção discursiva, na qual o sujeito manifesta seus pontos de vista, reconhece e reestrutura a voz alheia, compromete-se com sua palavra, que se pode dizer que há uma produção de texto e não apenas de redações. Assim, abre-se espaço para a compreensão do ensino da produção textual escrita, como uma prática social discursiva, que contribua para a mudança social, pela e com a linguagem (Fairclough, 1992), reconhecendo com Bakhtin (1992:313) que,

...A época, o meio social, o micromundo - o da família, dos amigos, conhecidos... -que vê o homem crescer e viver, sempre possui seus enunciados que servem de norma, dão o tom; são obras científicas, literárias, ideológicas, nas quais as pessoas se apóiam e ás quais se referem, que são citadas, imitadas servem de inspiração. 
Assim pensada, a pesquisa a se realizar, tendo como objeto, a produção textual como uma prática discursiva deveria caminhar no sentido de produzir conhecimentos que subsidiem ao professor, no exercício da docência, a orientar o aluno para ir além do domínio da organização sintática-semântica-pragmática do texto, reconhecendo e identificando em seus textos e em quaisquer outros, circulantes em sala de aula, as "visões de mundo" ali presentes, as diversas vozes e suas relações dialógicas, os valores que portam, os processos de subjetividade manifestados e os de identidade selecionados.

É esta concepção de escrita como prática discursiva que vai permitir a realização de uma educação linguística que permita uma tomada de consciência e ao mesmo tempo uma postura crítica diante das produções textuais que realizamos e daquelas às quais estamos submetidos.

\section{Referências bibliográficas}

ABAURRE, M.B.M e outras. Cenas de aquisição da escrita. Campinas. Mercado de Letras 1997.

Atividades de linguagem, textos e discursos. São Paulo. EDUC. 1999.

BAKHTIN, M. Marxismo e Filosofia da Linguagem. São Paulo, Hucitec, 1969 Estética da Criação Verbal. São Paulo, Martins Fontes, 1992.

Problemas da Poética de Dostoiévsky. Rio de Janeiro: Forense Universitária. 1981

BEAUGRANDE, R. A; DRESSLER, W.U. Introduction to Text Linguistics. London, Longman, 1981

BOURDIEU, P. O Poder simbólico. Rio de Janeiro. Bertrand Brasil. 1998.

BRANDÃO, H.N. Texto, gêneros do discurso e ensino. In: Chiappini, L. (Org) Gêneros do Discurso na Escola. São Paulo: Córtex. 2000.

BRONCKART, J.P. et .SCHNEUWLY, B. (Eds), Vygotsky Aujourd'hui. Paris. Delachaux et Niestlé. 1985.

BRONCKART, J.P. Perspectives et limites d'une diversification de l'enseignement du Français. Études de Linguistique Appliquée. Nouvelle Sèrie, 83. Paris. Didier-, Érudition, 1991.

CABRAL, M. Avaliação e escrita: um processo integrado. In: Fonseca, F.I. (Org) Pedagogia da escrita: perspectivas. Porto: Porto Editora. 1994. 
CHOULIARAKI, L.; FAIRCLOUGH, N. Discourse in Late Modernity. Edinburgh: Edinburgh University Press. 1999.

FAIRCLOUGH, N. Discourse and social change. Cambridge: Polite Press. 1992.

FARACO, C. Pesquisa aplicada em linguagem: alguns desafios para o novo milênio. D.E.L.T.A. vol 17 (especial) 2001.

FOUCAULT, M. L'archéologie du savoir. Paris, Gallimard, 1969

L'ordre du discours. Paris. Gallimard. 1971.

GARCEZ, L. A escrita e o outro. Brasília. UNB, 1998

GERALDI, J.W. Portos de passagem. São Paulo.Martins Fontes. 1991

Prática e Produção de Textos na Escola. Cadernos de Estudos Lingüísticos, 24. Campinas. 1993

GOES, M.C.R. A criança e a escrita: explorando a dimensão reflexiva do ato de escrever. In: Smolka, A. L. B. e de Goes, M. C. R. (Orgs) A Linguagem e o Outro no espaço escolar. Papirus,Campinas, 1993.

GINZBURG. C. Signes, traces, pistes. Racines d'une paradigme de l'indice. Le Debat, 6. Paris. 1980.

HALLYDAY, M.A. K. and HASAN, R. Cohesion in English. London, Longman, 1976

KOCH, I.V.; TRAVAGLIA L.C. Texto e coerência. São Paulo, Cortez, 1989. MOITA LOPES, L.P. Conferência proferida por ocasião do VI CBLA. Belo Horizonte, 2001.

OLIVEIRA, M.B.F. de. A concepção dialógica da linguagem: uma contribuição ao estudo da relação linguagem e cognição. Estudos de Psicologia,v.1, n.2 , 227-252, .Natal, UFRN, Edufrn. 1996. Passeggi, L.

Escrita e Ensino : questões teóricas e metodológicas . In: 1998.

. (Org) Abordagens em Lingüística Aplicada. Natal, Edufrn.

Relações dialógicas, vozes, instauração do outro e o ensino da produção textual. Trabalho apresentado em Mesa-Redonda no II Congresso Internacional da Abralin. UFCe. 2001 (a)

. Produções escritas e processos identitários: um estudo de texto de alunos do ensino fundamental. Linguagem e Ensino. Pelotas/RS Vol.4. número 1. Janeiro 2001(b). 
SCHNEUWLY, B. La construction sociale du langage écrit chez l'enfant. In J.P. Bronckart et B.Schneuwly (Ed.). Vygotsky Aujourd'hui. Paris. Delachaux et Niestlé. 1985.

. Diversification et progression en DFLM: 1'apport des typologies. Études de Linguistique Appliquée. Nouvelle Série, 83. Paris, Didier-Érudition, 1991

SILVEIRA, R, M.H. O processo de elaboração de textos: interpretando o "passar a limpo". Linguagem e Ensino, Pelotas p. 39-58, vol 1. n.2, 1998.

SMOLKA, A.L.B. A criança na fase inicial da escrita. São Paulo, Cortex, 1988.

de GOES, M.C. A criança e a linguagem escrita : considerações sobre a produção de textos. In: de Alencar, E.M.L.S. (Org), Novas contribuições da psicologia aos processos de ensino e aprendizagem. São Paulo: Cortez Editora, 1992.

VADERMARIN, V. T. Lições de coisas: concepção científica e projeto modernizador para a sociedade. Cadernos Cedes, Campinas, n. 52, p. 7487, 2000.

VAN DJIK, T. La ciência del texto. Barcelona. Paidós, 1983.

VYGOTSKY, L. Pensamento e linguagem. Lisboa, Antídoto. 1979. . A Formação Social da Mente.São Paulo.Martins Fontes. 1984. 